\title{
Virucidal Efficiency of Chemical Agents: A comparative Analysis
}

\author{
Md. Deen Islam, Tabassum Tasnim Auroni, Mst. Salma Khatun, Md. Shifat-E-Monjur, Mahmuda Yasmin, \\ Chowdhury Rafiqul Ahsan and Jamalun Nessa* \\ Department of Microbiology, University of Dhaka, Dhaka 1000, Bangladesh
}

\begin{abstract}
Present study was designed to explore the influences of different categories of chemical factors, such as organic solvents, oxidizing agents, anionic detergent and dye on persistence of locally isolated coliphages and shigaphages from clinical sewage samples. Thirty percent ethanol initiated 83.20 and $62.86 \%$ reduction in the number of coliphage and shigaphage plaques in our study respectively. Chloroform mediated decrease in our observation was $\mathbf{5 3 . 1 3}$ and $\mathbf{8 8 . 3 3 \%}$ for coliphages and shigaphages, respectively. The number of the shigaphage plaques was reduced by $62.5 \%$ following biphasic diethyl ether (DEE) treatment. About $72.66 \%$ of coliphages were deactivated after exposure to biphasic diethyl ether. Exposure of the isolated coliphages and shigaphages to $1 \%$ formalin had completely destroyed the viability of the bacteriophages. Coliphage survival in this investigation was $37.5 \%$ and $2.4 \%$ following treatment with 0.3 and $3.0 \%$ hydrogen peroxide respectively. The decrease in overall coliphage and shigaphage population was $95.83 \%$ and $94.14 \%$ while treated with $0.5 \%$ sodium dodecyl sulfate (SDS). The number increased for the viruses infecting $E$. coli by $\mathbf{9 . 5 2 \%}$ where the number of shigaphages declined by $14.63 \%$ while growing in presence of a divalent cation $\left[\mathrm{Ca}\left(\mathrm{NO}_{3}\right)_{2}\right]$. Coliphage and shigaphage populations were diminished by $61.76 \%$ and $53.48 \%$ respectively after treatment with the neutral red $(0.0075 \%)$ followed by exposure to visible light.
\end{abstract}

Keywords: Bacteriophage inactivation, Organic solvents, Oxidizing agents, Anionic detergent, Dye

\section{Introduction}

Bacteriophages are viruses specifically infecting bacteria, are harmless to humans, animals, and plants. Since the discovery of phages in 1915, they are being investigated to be utilized in human and veterinary medicine, wastewater treatment as well as in various agricultural settings ${ }^{1-2}$. Phages are appropriate to prevent or reduce bacterial colonization in livestock, to decontaminate carcasses and other raw products, to disinfect equipment and contact surfaces and to extend the shelf life of perishable manmade foods ${ }^{3}$. The curiosity for natural antimicrobial compounds has recently been enhanced due to alterations in consumer positions towards the usage of chemical preservatives in foodstuff and food processing surfaces.

Phage therapy has been explored for the treatment of diverse diseases, like diarrhea, cholera, dysentery, on several occasions with promising results ${ }^{4-5}$. The recent emergence of antibioticresistant pathogenic bacterial strains has motivated researchers to look for alternative means of disease control ${ }^{6-7}$. Therefore, research focused on isolating and understanding phages that could provide an additional tool to tackle the global vulnerability to antimicrobial resistance would be highly valued.

Many important illnesses such as gastroenteritis, poliomyelitis, aseptic meningitis, and some variants of hepatitis can be transmitted by viruses via the faecal-oral route. Contact with pathogenic viruses can happen when humans are exposed to drinking or recreational water that has been contaminated by wastewater. To prevent viral disease outbreaks, it is therefore essential that water be appropriately treated before it is brought into contact with humans.

Bacteriophages as well as animal viruses can be vulnerable to unfavourable physical and chemical factors, such as low and high temperatures, $\mathrm{pH}$, salinity, and ions. It seems that phage features in this field are highly diversified and may differ not only among families, but also within them. So far, anyone who is going to preserve phages should acquire adequate information about their relevant susceptibilities ${ }^{8}$. High bacteriophage resistance for external factors is important for stability of phage preparations. However, this feature is highly disadvantageous for research and commercial purposes when maintenance of the structural integrity and particular activities of viral strains could be crucial. Inactivation of phages in different environments is multifactorial. It is known that the variation of one factor that influences phages may change phage sensitivity to the others ${ }^{9}$. The growing interest of the pharmaceutical and agricultural industries in phages demands new data on phage survivability and methods of their preservation. The aim of the present work was to isolate coli phages and shigaphages from nature, determine their titre and explore their comparative vulnerabilities towards some chemical 
agents such as organic solvents, oxidizing agent, anionic detergent and vital dye. The possible effect of divalent cat ion on growth of coliphages and shigaphages was investigated too.

\section{Materials and Methods}

\section{Collection of sample from sampling site}

Raw sewage sample was collected from the outer ward unit of an urban based hospital where the whole hospital's sewage effluents were accumulated and later passed to the municipality drainage system. The samples were dark ash in colour and had strong odour.

\section{Sample preparation}

The sewage sample was passed through the Whatman \#1 filter paper $(110 \mathrm{~mm}$ x 100 circles, Whatman International Ltd. Maidstone, England.) two times to remove most of the suspended debris. Filtrate $(1.5 \mathrm{ml})$ was collected into sterile Eppendorf tube and centrifuged at 12 thousand rpm for 15 minutes. The supernatant was filtered through $0.22 \mu \mathrm{m}$ syringe filter (Millipore USA) to remove the bacterial population. The final filtrate was collected into a sterile vial containing only the viruses ${ }^{10}$.

\section{Bacterial strains and media}

Two bacterial species (Escherichia coli K-12 and Shigella flexneri ATCC 12024) were employed to isolate the bacteriophages to be used for the determination of the effect of various chemical treatments on them. Luria-Birtani (LB) medium (Sigma Chemical Company, St. Louis, MO, US) was used for the cultivation of the two bacterial population.

Preparation of young culture

Loopful of bacterial culture (E. coli and S. flexneri) were inoculated into separate tubes containing LB broth (Sigma Chemical
Company, St. Louis, MO, US). The inoculated broth was incubated for four hours in a shaking incubator at $37^{\circ} \mathrm{C}$.

Determination of the effects of various chemical agents on the viability and propagation of different bacteriophages

The standard protocol ${ }^{11}$ for phage propagation was adapted in the current research, where $0.5 \mathrm{ml}$ of prepared (centrifuged and milipore-filtered) sewage sample was mixed with $0.5 \mathrm{ml}$ of test chemical (double strength chemical) and was used as the working concentration. The mixture was incubated at room temperature for 30 minutes. For control, $0.5 \mathrm{ml}$ of prepared [centrifuged with (Hettich Mikro 120 centrifuge machine, Germany) membrane filtered] sewage sample was mixed with 0.5 $\mathrm{ml}$ of sterilized distilled water in it. This mixture was also incubated at room temperature for 30 minutes. Then 100 il of treated sewage sample and 100 ìl of young culture of specific bacteria were added into $5 \mathrm{ml}$ of LB soft agar (0.8\%). After mixing gently by hand, this mixture was poured on LB agar plate and briefly swirled by gentle sidewise movement for even and uniform distribution of the top agar over the LB agar in the Petri-dish. The top agar was allowed to be solidified. The same process was followed for the control and duplicate plates. After incubating the plate at $37^{\circ} \mathrm{C}$ for overnight, the cleared zones/ plaques on the bacterial lawn were observed. The plaque forming units $/ \mathrm{ml}$ (pfu/ml) of the supplied treated and untreated sewage sample was counted and calculated for each treatment. Comparison between the counts obtained for the treated and untreated sewage sample was done to understand the effect of the treatments on the viability and propagation of the specific bacteriophage that have been tested in the experiment. Various treatments used is summarized in Table 1.

Table 1. Chemical treatments used for phage inactivation in this study

\begin{tabular}{|c|c|c|c|}
\hline Category & Treatment & Working concentration & Incubation temperature and time \\
\hline \multirow[t]{4}{*}{ Organic solvents } & Ethanol & $30 \% \mathrm{v} / \mathrm{v}$ in water & 30 min at room temperature \\
\hline & Chloroform & $\begin{array}{l}\text { Biphasic ( } 1 \text { volume of } \\
\text { chloroform }+2 \text { volume } \\
\left.\text { of } \mathrm{H}_{2} \mathrm{O}\right)\end{array}$ & 30 min at room temperature \\
\hline & Diethyl ether (DEE) & $\begin{array}{l}\text { Biphasic (1volume of } \\
\left.\mathrm{DEE}+2 \text { volume of } \mathrm{H}_{2} \mathrm{O}\right)\end{array}$ & 30 min at room temperature \\
\hline & $\begin{array}{l}\text { Formalin ( } 37 \% \text { aqueous solution } \\
\text { of formaldehyde gas) }\end{array}$ & $1 \%$ in $\mathrm{H}_{2} \mathrm{O}$ & 30 min at room temperature \\
\hline Oxidizing agent & $\begin{array}{l}\text { Hydrogen peroxide }\left(\mathrm{H}_{2} \mathrm{O}_{2}\right) \\
\mathrm{H}_{2} \mathrm{O}_{2}\end{array}$ & $\begin{array}{l}0.3 \% \mathrm{v} / \mathrm{v} \text { in water } \\
3 \% \mathrm{v} / \mathrm{v} \text { in water }\end{array}$ & $\begin{array}{l}30 \mathrm{~min} \text { at room temperature } \\
30 \mathrm{~min} \text { at room temperature }\end{array}$ \\
\hline Anionic detergent & Sodium dodecyl sulfate (SDS) & $0.5 \%$ in water & 30 min at room temperature \\
\hline Divalent cation & Calcium nitrate $\left[\mathrm{Ca}\left(\mathrm{NO}_{3}\right)_{2}\right]$ & $0.05 \%$ added into media & \\
\hline Dye & Neutral red & $\left(0.0075 \% \mathrm{w} / \mathrm{v}\right.$ in $\left.\mathrm{H}_{2} \mathrm{O}\right)$ & $\begin{array}{l}30 \text { min at room temperature } \\
\text { Exposure to bright light No exposure } \\
\text { to bright light }\end{array}$ \\
\hline
\end{tabular}




\section{Results and Discussion}

Studies on the antimicrobial activities of different compounds have been carried out previously in the aim of finding ways to eliminate bacterial infections among humans and animals and reduce microbial populations in food products, packaging, and equipment. Nevertheless, information on virucidal activity is much less prevalent than that concerning bactericidal, fungicidal, and sporicidal activities. Various external physical and chemical factors, such as temperature, acidity, salinity, and ions, determine the occurrence, viability, and storage of bacteriophages. These versatile physical and chemical applicants can inactivate a phage through damage of its structural integrity by affecting capsid or envelope structure, facilitating lipid loss, and/or initiating NA structural deviation ${ }^{11}$. Few of these attributes may positively interfere with the endurance and/or the infection cycle of particular phage members and thus enhance their survival. However, the ability of bacteriophages to survive under unfavourable conditions is highly diversified. Interestingly, the membership in the same family and even close structural similarity may not determine a phage's features and resistance to external factors. Hence, different members within a family of viruses can exhibit very different susceptibilities against the same antimicrobial agent.

Bacteriophages infecting $E$. coli and phages specific for S. flexneri sustaining in clinical sewage were isolated in summer time (March 2014) and subsequently enumerated. Most (89\%) members of the isolated phage population were specific for $S$. flexneri. Only (11\%) eleven percent of the isolated viruses had infected E. coli only. Proportion of various bacteriophages in nature varies widely with time and place. Virus inactivation experiments were conducted using two groups of phages specific for $E$. coli and $S$. flexneri and a range of antimicrobial components. We explored the influences of different categories of chemical factors, such as organic solvents, oxidizing agent, detergent and dye on persistence of isolated coliphages and shigaphages in this research.

\section{Effect of organic solvents on coliphages and shigaphages}

Various organic solvents such as ethanol, chloroform, diethyl ether and formalin were tested to clarify their potency (Figure 1) to inactivate isolated coliphages. Ethyl alcohol may dissolve the lipid molecules of viral envelope by reducing hydrophobic interaction among lipid molecule ${ }^{12}$. It can also interact with the structural proteins of the viruses and denature them. Thirty percent ethanol initiated $83.2 \%$ reduction in the number of coliphage plaques in our study. However, ethyl alcohol mediated reduction for shigaphages was comparatively lower (62.86\%) than that of coliphages.

Organic solvents like chloroform do not permit lipid clustering driven by hydrophobic interactions. It may interfere with proteinprotein and lipid-protein interaction in the viral membrane by weakening the hydrogen and electrostatic bond ${ }^{12}$. As a result, bacteriophage survival and propagation could be inhibited. Chloroform mediated decrease in our observation was 53.13\% and $88.33 \%$ for coliphages and shigaphages, respectively. AlMola and his team ${ }^{13}$ reported complete inactivation of coliphages isolated from raw sewage by chloroform treatment for thirty minutes.

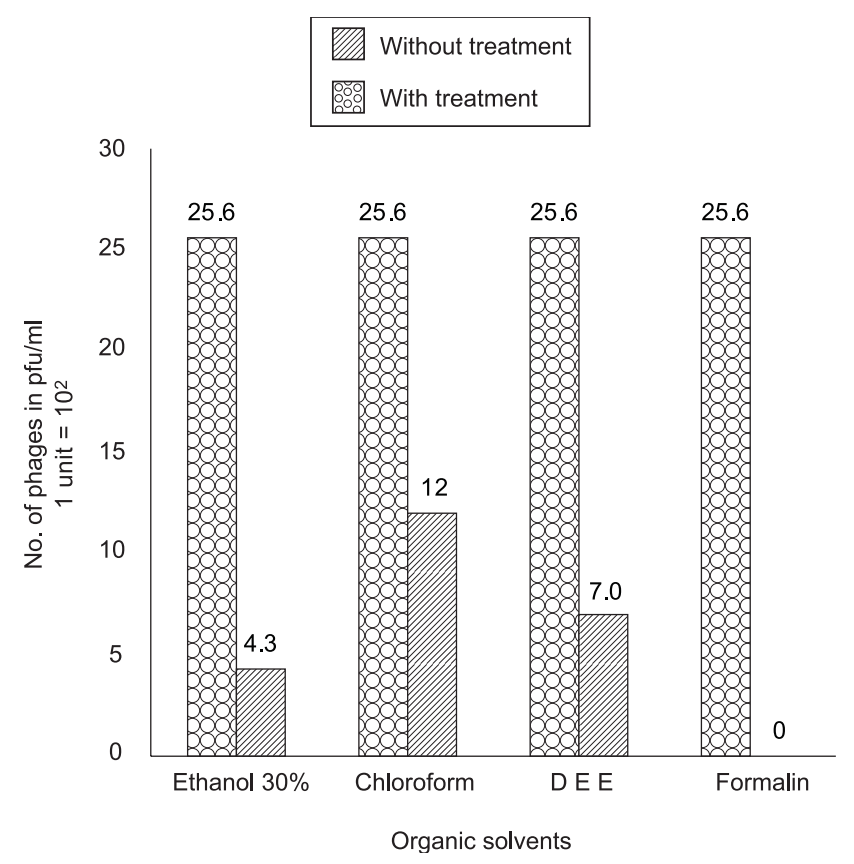

Figure 1. Effect of organic solvents on coliphages.

Some phages contain lipids as structural components of their virions. Sands and Lowlicht ${ }^{14}$ showed that lipids are essential for maintaining the virus ability to infect new host. Lipids are soluble in nonpolar solvents such as ether and chloroform, which are capable of extracting and disrupting the lipid components of the phages by interfering with the hydrophobic interactions between lipid molecules. Any disruption of the lipid components may lead to a loss of viability of the virus. In our experiment, the number of the shigaphage plaques was reduced by $62.5 \%$ following biphasic DEE treatment. However, 72.66\% of overall coliphages were completely deactivated after a 30 minute period of exposure to biphasic DEE (Figure 2).

Exposure of the isolated coliphages and shigaphages in this study to $1 \%$ formalin for thirty minutes had completely destroyed the viability of the bacteriophages. Formalin exerts its antiviral action through alkylation of sulfhydryl, amino, hydroxyl and carboxyl groups on capsid proteins and imino groups of nucleic acids ${ }^{12}$. As a consequence, metabolic activities could critically be hampered and be followed by complete viral inactivation. The observed $100 \%$ deduction of shiga and coliphages by formalin in our work strengthens the previous reports and identifies formalin as the most potent antiviral agent among the three different organic solvents tested. 


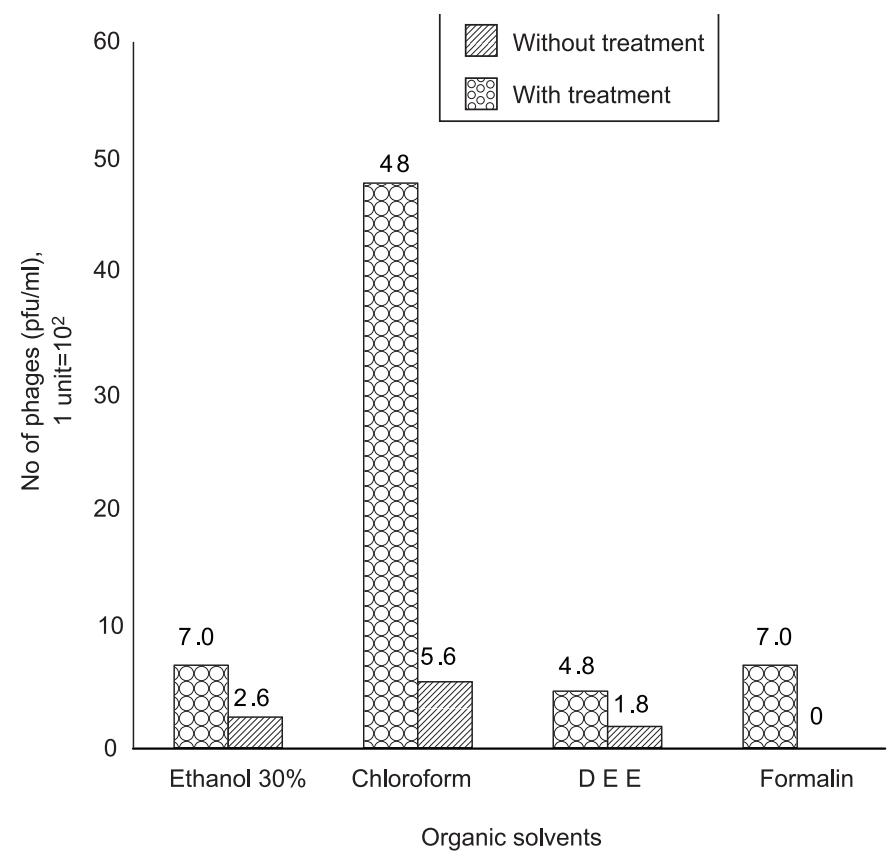

Figure 2. Effect of organic solvents on shigaphage.

Survival of coliphages and shigaphages after oxidizing agent treatment

As a potent oxidizing agent, $\mathrm{H}_{2} \mathrm{O}_{2}$ may facilitate oxidization of the reduced protein and lipid molecules in virion structure. DNA damage may be induced indirectly as a consequence of formation of secondary reactive species formed by the reaction of free radicals. DNA damage may be the result of interaction of free radicals with enzymes involved in replication or repair of DNA ${ }^{15}$. Subsequently, phage population could be denatured and deactivated. Coliphage survival in this investigation was $37.5 \%$ and $2.4 \%$ following treatment with 0.3 and $3.0 \% \mathrm{H}_{2} \mathrm{O}_{2}$ respectively (Figure 3). Shigaphages isolated in this work showed more

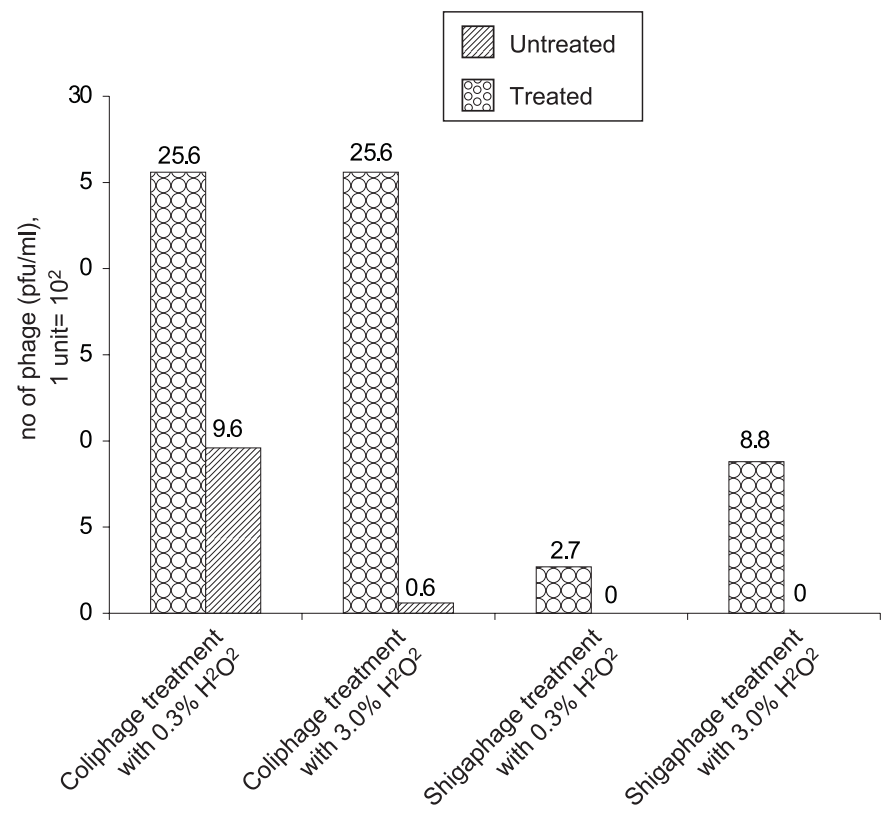

Figure 3. Effect of oxidizing agent $\left(\mathrm{H}_{2} \mathrm{O}_{2}\right)$ on coliphage and shigaphage. vulnerability than tested coliphage population towards $\mathrm{H}_{2} \mathrm{O}_{2}$. Bacteriophages specific for $S$. flexneri had zero percent survival rate while treated with hydrogen peroxide either at $0.3 \%$ or $3 \%$ concentration.

SDS influence on shigaphage and coliphage population

The antiviral activity of SDS is poorly investigated against coliphages and shigaphages. The decrease in overall coliphage and shigaphage population in this work was 95.83 and $94.14 \%$ while treated with $0.5 \%(\mathrm{w} / \mathrm{v})$ SDS for thirty minutes (Figure 4). SDS is an anionic detergent that might solubilise viral envelope and disrupts capsids in to separate polypeptides and thus negatively interfere with the bacteriophage survival and integration ${ }^{12}$. 0.5\% SDS inhibited the growth of $S$. flexneri but did not inhibit the growth of E. coli.

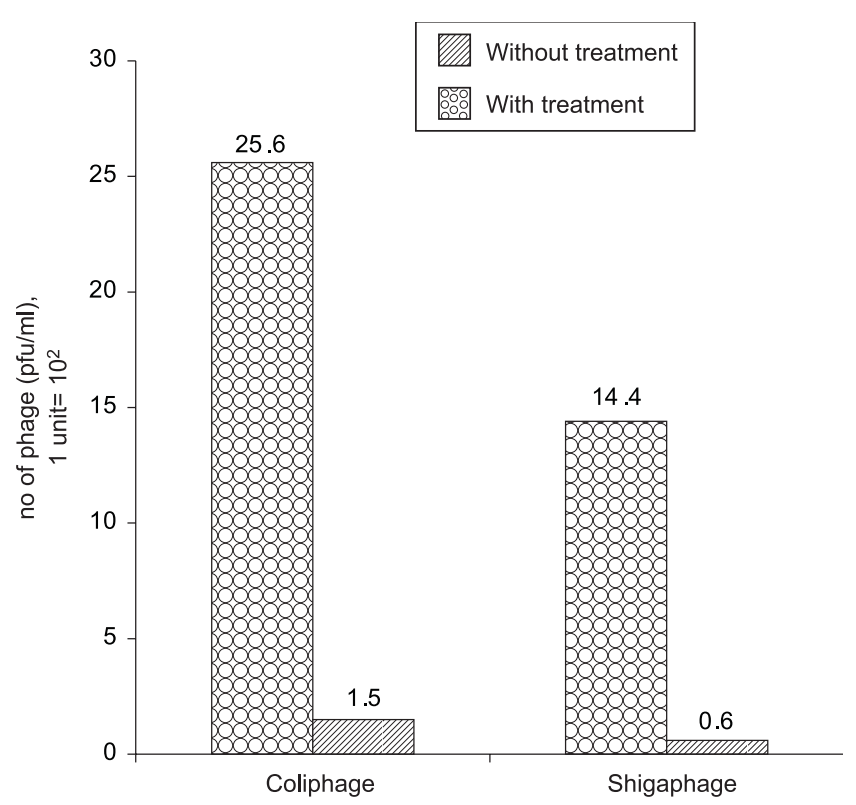

Figure 4. Effect of anionic detergent $(0.5 \% \mathrm{w} / \mathrm{v} S \mathrm{SD})$ on coliphage and shigaphage

Effect of divalent cation $\left[\mathrm{Ca}\left(\mathrm{NO}_{3}\right)_{2}\right]$ on coliphage and shigaphage

The inclusion of certain divalent cations in the media may enhance the adsorption ${ }^{12,18}$ of bacterial viruses to the host cell receptors and also may increase the number and size of the plaques formed. Each phage has characteristic cation requirements that are related to the phage rather than to the host cell surface. Some bacteriophages require Calcium ions either for adsorption or during phage multiplication. With coliphage $\mathrm{T} 5^{16}$, a typhoid phage and lactic streptococcus phages ${ }^{17}$, Ca was not necessary for adsorption but apparently acted at an early stage in phage synthesis. However, instead of increasing the number of both coliphages and shigaphages declined in this study while growing in presence of $0.05 \% \mathrm{Ca}\left(\mathrm{NO}_{3}\right)_{2}$ (Figure 5). The no of phage diminish for the viruses infecting $E$. coli and $S$. flexneri while 
treating with divalent cat ion was $7.27 \%$ and $14.63 \%$ respectively. Puck $^{18}$ with coliphages of the T series, produced evidence that there were a number of stages in the process of phage invasion. He suggested that the first step of adsorption involved electrostatic forces that were supplied by cations of the medium and which permitted reversible attachment of phage to cell surface. Thus divalent cation stabilized the coliphages more than that of shigaphages.

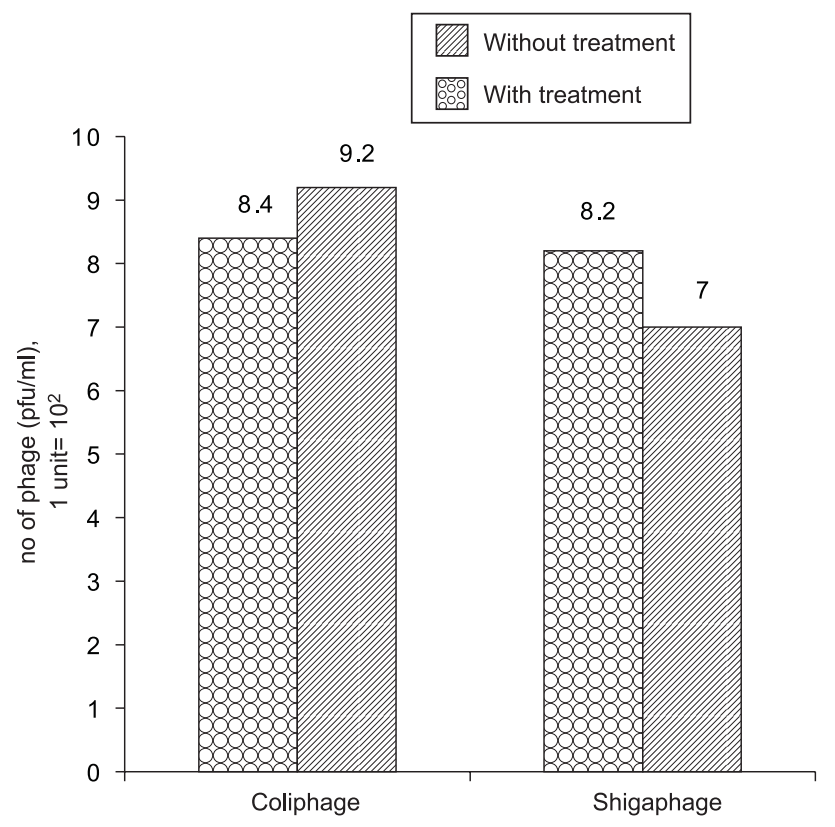

Figure 5. Effect of divalent cation $\left[0.05 \% \mathrm{w} / \mathrm{v} \mathrm{Ca}\left(\mathrm{NO}_{3}\right)_{2}\right]$ on coliphage and shigaphage

\section{Effect of neutral red on coliphage and shigaphage}

Photodynamic inactivation of bacteriophages by neutral red has previously been reported. Neutral red would bind to the viral nucleic acid, and change it to be susceptible to inactivation in the presence of visible wavelength of light ${ }^{12}$. It has been known for many years that some viruses form complexes with certain vital dyes such as neutral red, proflavine, and toluidine blue, and that these complexes are subject to rapid biological inactivation when exposed to visible light in the presence of molecular oxygen ${ }^{19}$. This led to interest in the possibility of using this system for the treatment of superficial skin infections, and numerous studies have been undertaken in animals as well as in man. coliphage and shigaphage populations were diminished by 61.76 and $53.48 \%$ respectively after treatment with the neutral red $(0.0075 \%)$ followed by exposure to visible light in the current research (Figure 6). Besides, the results of this study have shown that Photodynamic inactivation by neutral red was able to exert a relatively stronger effect on coliphages than shigaphages.

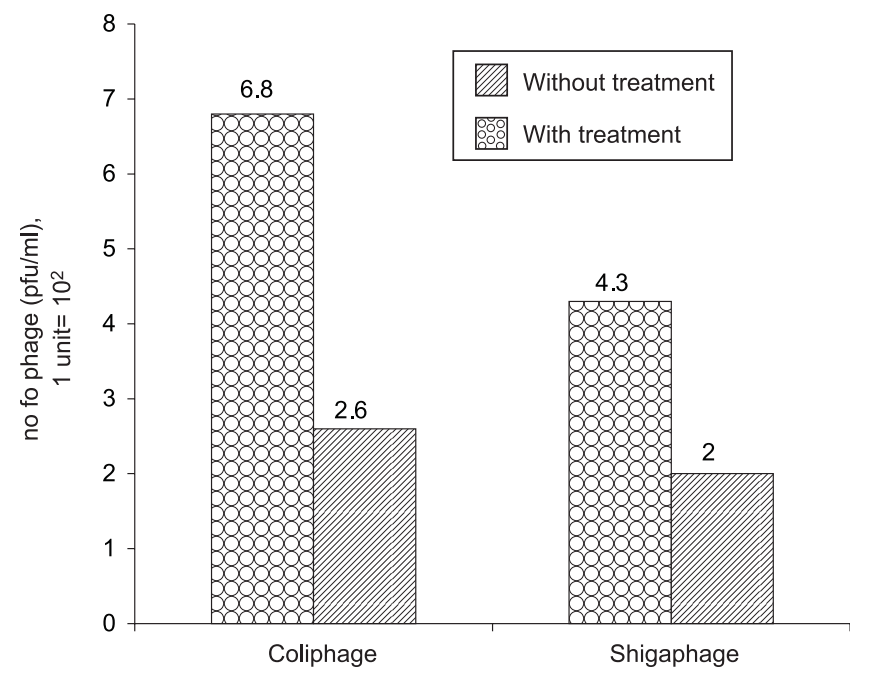

Figure 6. Photoinactivation of coliphage and shigaphage by neutral red $(0.0075 \% \mathrm{w} / \mathrm{v})$

The selection of a specific phage for bio-control applications requires fulfilling a number of characteristics, such as: be strictly virulent, display a broad host range, be unable to perform generalized transduction, and not perform lysogenic conversion of its host. Also, detailed molecular characterization of the phage genome is mandatory to exclude the presence of any toxin genes or antibiotic-resistance genes. A rigorous risk assessment is necessary prior to using phages and phage-derivative products to ensure maintenance of standard biosafety level. Structure and composition wise viruses are the most diverse groups of entities among the microorganisms. Previous researchers showed that even small differences in the composition of the viral genome and proteins have impact on disinfection. A better understanding of the complex problem of phage sensitivity to external factors may be useful not only for those interested in pharmaceutical and agricultural applications of bacteriophages, but also for others working with phages.

\section{References}

1. Choi J, Kotay SM and Goel R. 2011. Bacteriophage-based biocontrol of biological sludge bulking in wastewater. Bioeng Bugs. 2(4): 214-217.

2. Dhevagi P and Anusuya S. 2013. A novel approach for pathogen reduction in wastewater treatment. J Environ Sci Health. 11: 12.

3. Sharma M, Patel JR, Conway WS, Ferguson S and Sulakvelidze A. 2009. Effectiveness of bacteriophages in reducing Escherichia coli O157:H7 on fresh-cut cantaloupes and lettucet. J Food Prot. 72(7): 1481-1485.

4. Alexander S, Zemphira A and Glenn. 2001. Bacteriophage Therapy. Antimicrob Agents Chemother. 45(3): 649-659.

5. Summers WC. 2001. Bacteriophage therapy. Annu Rev Microbiol. 55: 437- 451 .

6. Ho K. 2001. Bacteriophage therapy for tacterial tnfections: Rekindling a temory from the pre-antibiotics era. Perspect Biol Med. 44(1): 1-16.

7. Alam M, Akhter MZ, Yasmin M, Ahsan CR and Jamalunnessa. 2011. Local bacteriophage isolates showed anti-Escherichia coli 0157:H7 potency in an experimental ligated rabbit ileal loop model. Can J Microbiol. 57: 408-415. 
8. Ackermann HW, Tremblay D and Moineau S. 2004. Long-term bacteriophage preservation. WFCC Newslett. 38: 35-40.

9. Muller-Merbach M, Rauscher T and Hinrichs J. 2004. Inactivation of bacteriophages by thermal and high-pressure treatment. Int Dairy J. 15: 777-784.

10. Moni S, Alam M, Ahsan CR, Jamalunnessa and Yasmin M. 2009. Occurrence and distribution of bacteriophages infecting pathogenic bacteria in sewage samples around Dhaka city, Bangladesh. Dhaka Univ J Biol Sci. 18(2): 173-180.

11. Sambrook J and Russell DW. 2001. Molecular cloning. In A Laboratory Manual, Vol 1, pp 225-231. Cold Spring Harbor Laboratory, Cold Spring Harbor, New York.

12. Brooks GF, Butel JS, Morse SA and Jawetz E. 2001. Jawetz, Melnick and Adelberg's Medical Microbiology, $22^{\text {nd }}$ edn, pp 328-329. Appleton and Lange, New York.

13. Al-Mola GA and Al-Yassari IH. 2010. Characterization of E. coli phage isolated from sewage. AL-Qadisiya J Vet Med Sci. 9(2).
14. Sands JA and Lowlicht RA. 1976. Temporal origin of viral phospholipids of the enveloped bacteriophage phi 6. Can J Microbiol. 22(2): 154-158.

15. Gille JJ, Wienties NM, Lafleur MV, Joenje and Retel J. 1996. Biological consequences of DNA damage introduced in bacteriophage PM2 DNA by hydrogen peroxide mediated free radical reactions. Carcinogenesis. 17(1): 5-11.

16. Luria SE and Steiner DL. 1954. The role of calcium in the penetration of bacteriophage T5 into its host. J Bacteriol. 67(6): 635-639.

17. Potter NN and Nelson FE. 1953. Role of calcium and related ions in proliferation of lactic streptococcus bacteriophage. J Bacteriol. 66(5): 508-516.

18. Puck TT. 1953. The first steps of virus invasion. Cold Spring Harb Symp Quant Biol. 18: 149-154.

19. Wallis C and Melnick JL. 1964. Irreversible photosensitization of viruses. Virology. 23: 520-527. 